\title{
Countermeasures Analysis on the Network and Its Psychological Education of College Students
}

\author{
Huayao $\mathrm{Xu}$ \\ Handan Polytechnic College \\ Handan,056001, China
}

\begin{abstract}
Based on the Students' Internet usage exposition, this paper analyzes the necessity of the ideological and political education network and elaborated college students from the era of ideological and political characteristics of the network, sharing resources and vast amounts of information, virtualization and other aspects of equality Education network feasibility. Finally, from the ideological construction of the network platform, it is to strengthen the network of ideological and political education team building, promote ideological and political education network of timeliness, and deepen the expansion of the network to enhance the relevance of education and the five aspects of education network political education network of ways and means.
\end{abstract}

\section{Keywords- Political; Undergraduate Education; Network}

\section{INTRODUCTION}

China Internet Network Information Center released the "China Youth Internet Behavior Survey Report 2009", it shows that college studentsare one of the most active groups of the network, the group usage in most network applications are the highest. As we can see, the network has become an integral part of student life. However, college students are in a critical period of building outlook on life and in the formation of worldview, and network information patchwork world, is whether good orbad.College Internet users quickly and easily get massive knowledge, some harmful reactionary information, and violent and pornographic information has a huge psychological impact on college students values, ethics, behavior and personality, on the traditional ideological and political education of college students challenge mode. Network is a product of the times, it is important to use the network that has become an integral part of everyday life college students' study and work. Universities as places to promote social progress and human culture should not become an obstacle to the development of the times, so as ideological and political education of college students must quickly discover this phenomenon and fully utilize. Interest is the best teacher of learning, since in college, students are interested in using the network, and then the network is bound to become an important tool in the new situation of ideological and political education of college students. Use Web media, student interest-driven, ideological and political education for college as guide, college students' political and ideological education is bound to adapt to the times.

\section{ANALYSIS ON A CONTEMPORARY STUDENTS' PSYCHOLOGICAL UNHEALTHY PROBLEM}

\section{A. Adapt to the New Environment}

For those whojustentered the university campus, college students feel that everything is so strange, new collective, a new lifestyle and a new learning environment for all college students have demonstrated in front of the high school, the idea in the past that "we do not hear something out of the window "had completely different lifestyle. Faced with a new life, many college students and even some simple, basic labor are not willing to do it. In addition, the study, high school education just admitted to the University as a learning objective. Their education is compulsory, closed, and now in the university campus, many students in this loose and free learning environment have their own learning purpose and motivation is not very clear, they are slack, and there is a gap between the ideal and the reality, which is not acceptable. All these will easily turn out to be anxious, depressed negative state of mind.

\section{B. They Have Difficulties inInterpersonal Communication}

Entering the university, students are from all corners of the face; college students leave their parents and go into the collective life. They are eager to get their own copy of intimate friendship relationship, but in reality, they have lack of interpersonal skills.Among the usual life, for the college students, on the one hand, there are differences of regional culture, on the other hand, they are always self-centered, and they do not listen carefully to the views of others, from the perspective of other people to consider the issue. So that they and cannot get a true friendship, so that they are in the face of difficulties, they are not confidant, prone to paranoia and other psychological problems, they also often feel inferior, which is increasing lack of confidence, also increasing the psychological pressure.

\section{Confusion inEmotion and Love}

Currently, the college students are in the physical development of young growth period.During college, dating phenomenon is relatively common, but they do not know what true love is, they are in the search for what kind of love they want. However, they are lack of life experience, and they are emotionally impulsive, it can easily lead to depression and other psychological phenomena. Once they lose the romance, they are difficult to come out from the pain, it is often because of improper handling emotional problems and unable to extricate themselves into a painful confusion, 
which directly affects the mental health of college students issue. Network of mental health education refers to mental health use of network technology and related functions in a variety of ways to help visitors solve their psychological problems, to improve their mental quality level process. Today, the web medium of mental health education mixed reviews.Praise mostly is onpropaganda network in the world as a new human interaction patterns across many obstacles to traditional educational psychology. It has opened up a hightech, high-information, high-coverage, high efficiency, ultratraditional means of educating a new heart. The denigration stressed summarized in the traditional accumulation of psychological education and in practice, it can play an important role in many of the educational experience, such as acquisition, analysis and intuitive non-verbal information, consulting stable relations consultants play charisma face infections that become serious flaws network psychological education. Objectively speaking, with modern technologybased psycho-educational support network for its own characteristics, it cannot completely replace the traditional psychological education. But, in school, especially in the development of network-based psycho-educational university, it is to make up the psychological education gap, and it is an effective way to solve the fetters of Psychological Education pace of rapid development.

\section{Challenges OFMENTAl HEALTh EDUCATION FACED BY STUDENTSUNDER NETWORK ENVIRONMENT}

Network technology from its birth to the moment has been carrying values of different individuals or groups, political views and ethics, etc. Therefore, it can have a positive impact on either college students; it may become negative impact of intermediaries.

Impact on Cognition: The network expanded information sources of college students; college students broaden their horizons, and expand the amount of information. Students can search for the information they are interested in via the network search engine.So you can get the latest information in a very short period of time, so that they can understand the outside world, which makes college students release from knowledge, information of the school and the teacher. They can be freedom of travel in the ocean of knowledge and information, and draw useful nutrition to improve their quality, broadens their horizons, which can develop their sense of innovation and global awareness. Second, the networks for college students areto improve their quality and to provide new opportunities for development. Faced with a lot of information, requiring university students must have identification, selection, absorb and apply new knowledge. To have the opportunity is to capture the sensitivity; otherwise,it will pass a good chance. Faced with a large number of information, they have to identify the merits of marriage, by analogy insight and imagination; otherwise, it will follow in the footsteps behind others, which is difficult for innovation. Faced with strange spam, they should have the ability to resist; otherwise, they will indulge in adventure that would be distracting and time-consuming [1]. However, the network will have a lot of negative impact on the awareness of college students. Prolonged exposure to the network, they will reduce the perception of college students, overexposure can cause cognitive paralysis.

Effects of Internet on Students' Personality: network can greatly strengthen the college students' self-awareness. To some extent, it can be able to demonstrate the independence of college students, no centralized nature of autonomy and domination, the network can enhance the awareness of the concept of equality and democracy. But, it can also lead to the expansion of self-consciousness and collective consciousness of the weak; virtual, anonymous characteristics of the network. Itallows college students to show great indulgence and arbitrary, this is helping those who are more introverted and able to restrain themselves in real life exercises and in training students in their own networks guts, in honing their character to express repressed emotions and inner discontent. But on the other hand, it can lead to uncontrolled behavior of college students, speaking bad, bad manner. According to the observation of author in cafes and network bars, those who are usually very quiet, very polite student, have become a different persons in the network, and even some female students in the network swept woman's image and unfolds the shrew image of "Bad manner". Especially in playing different roles in the network game, it is leading to a double personality or multiple personality disorder. Finally, Internet pornography will lead to deviations from students' psychological metamorphosis and behavior.

\section{PSYCHOLOGICAL PROBLEM IN EDUCATION BRINGS FROMEDUCATIONAL NETWORK DEVELOPMENT}

Learning psychology is the core study of educational psychology. People have to learn some common law under different conditions and background.But this commonality in specific situations has different forms and requirements. First, the education network in the context of individual faces no emotion, agile and mechanical performance of the network, which is asking them to keep on learning content and the learning process for conscious attention in a long time. It arouses strong learner motivation, only the application of multimedia technology is enough. Second, emotional material and actionable content have a strong expressive thing in the network based on the easy-to-analog display, which is easy for learner to grasp the rapid development that is beneficial to the image of thinking, storage-rich representation. And logical and abstract high basic theory like history, literature and other content cannot be displayed directly that led tobe difficult to develop homogeneous development and strengthening of semantic memory learner abstract logical thinking. Third, in the education network of learning, the learner has contact the experienced in the computer that prompts the implicit mental operations and the imagination is too unreal, it detached from reality, the depth of thinking and processing are also worrisome. Network evaluation of learner outcomes is based on a certain pattern and structure of the series to carry out, while the freedom of association and expression of learners are colorful, rigid evaluation may not fully reflect the actual situation of the learner, or even mislead learners to think mechanically. 
Network technology strategy in virtual reality of using the case (especially sudden state) has a considerable gap, changing the "Network energy and low energy reality", it must be under the strategy and skills network effectively to migrate to realities. Particularly worth mentioning is that it repeated attempts to operate the network itself directly to the learning outcomes rather than the process of thinking process that will lead to too much emphasis on the results of the learners themselves and ignore the fun process. Meanwhile, multiple occurrences of the same operation may also lead to the motivation to complete the task thatis reduced, which is not conducive to the formation of rigorous learning attitude.

\section{ESTABLish a Universal NETWORK CHANNELS OF KNOWLEDGE OF MENTAL HEALTH EDUCATION}

As for the mental health education for college students, we must give full play to the role of teaching the network channels. Take advantage of college radio stations, television stations, the campus network, newspaper magazine, windows, billboards, etc., with particular attention to the ideological, moral, and legal foundation courses integration. The mental health education courses included Morality and legal basis of the teaching program, and taught students as key content and related courses in the syllabus, with some courses combined.For example, students of the hotel management, tourism management, and other professional have to learn mental health and nutrition knowledge; medicine, nursing, public health professional students learn medical ethics, bioethics. The major of education, psychology, management, sociology, and marketing professionals' students learn counseling, management psychology, social psychology, consumer psychology; law and literature, history, philosophy majors and mental health education, ideological and political education psychology, political psychology, criminal psychology and other courses content are linked. We should cultivate students with scientific, civilized and healthy lifestyle, with noble sentiments;so they can have manners perfect personality, positive attitude towards life, gentle temperament, and civilization.

\section{A. Establish a Network Mechanism of Mental Health Education}

Students' Mental Health Association organized to mobilize the enthusiasm of students to participate in mental health education, grasped students' the psychological problems, helpedstudents self-education, self-management, self-service, the ability to self-improvement. Establish similar "intimate sister" mentality mailboxes, casework counseling for individual issues, giveguidance for the issues of universal significance of positive education for all students. Try to solve specific psychological problems in the bud. For all students, conducta series of mental health education practice. On the one hand, guide students to participate in mental health practice, making it selfpreservation, self-control, self-motivation, self-development and self-cognitive abilities rising; on the other hand, through lectures, theme salon, students fully understand mental health basics and methods of self-psychological adjustment eliminate negative emotions, enhance self-psychological adjustment. For example, the creation of new students adapts to campus life psychology lectures, sophomore can be offered with life planning, career planning guidance lectures, grade three universities students can be offered with postgraduate study, employment, career guidance and so forth, seniors University students offers graduate mental health lectures and so on. Teachers in each semester of mental health education and counseling center should have a plan to open to all students about the interpersonal relationships, self-awareness, love life, respect for life and other seminars.

\section{B. Ensure the Effectiveness of the Teaching Process}

In traditional schools, teachers on the basis of the analysis of students have a clear purpose by developing "recent developments". Through personal qualities, knowledge, ability to penetrate in the teaching system andto exhibit art, flexible regulation of educational context, use actual scene to observe learner assessment to ensure both learners acquire knowledge, but also through it can learn the process of continuous self-directed by itself. Although online education learners can choose to maximize learning, but a sequence selected must operate in a networked tip for emergencies, lightning thinking is not easy to control, meaning learners are difficult to effectively perceive. The emotional state of the learning process of the network is also vague, but the best time is the effective use of these.

\section{CONCLUSIONS}

strengthen the network of ideological and political education team building, promote ideological and political education network of timeliness, and deepen the expansion of the network to enhance the relevance of education and the five aspects of education network political education network of ways and means. establish a universal network channels of knowledge of mental health education by establishing $a$ network mechanism of mental health education and ensure the effectiveness of the teaching process.

\section{References}

[1] Huang Fusheng.Build mental health education and counseling network platform college students $[\mathrm{J}]$ Qiannan Normal University, 2006,06: 53-57.

[2] GuoMingxia. Education Network mechanism mental health of college students [J] Health Vocational Education, 2008,19: 157-158.

[3] Cao Haixian, Xu Cunyan.Television network spread expansion of Mental Health Education [J] audio-visual education research, 2008,03: $42-44+49$.

[4] Yang Kang. College Students' Mental Health Education Network construct [J] Lanzhou Institute of Education, 2010,06: 72-73.

[5] BaoJihua relying mental health education to build "network" Graduate Management System [J] World Education Information, 2005,08: 36-37.

Zhou Pei.Building network system Vocational College Students' Psychological Health Education [J] Journal of Zhengzhou Railway Vocational and Technical College, 2013,02: 71-72. 